\title{
Development of carbonaceous tin-based solder composite achieving unprecedented joint performance
}

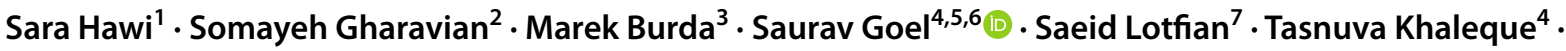 \\ Hamed Yazdani Nezhad ${ }^{1,8}$
}

Received: 20 August 2021 / Accepted: 9 December 2021 / Published online: 30 December 2021

(c) The Author(s) 2021

\begin{abstract}
Weight reduction and improved strength are two common engineering goals in the joining sector to benefit transport, aerospace, and nuclear industries amongst others. Here, in this paper, we show that the suitable addition of carbon nanomaterials to a tin-based solder material matrix (C-Solder ${ }^{\circledR}$ supplied by Cametics Ltd.) results in two-fold strength of soldered composite joints. Single-lap shear joint experiments were conducted on soldered aluminium alloy (6082 T6) substrates. The soldering material was reinforced in different mix ratios by carbon black, graphene, and single-walled carbon nanotubes (SWCNT) and benchmarked against the pristine $\mathrm{C}$-solder ${ }^{\circledR}$. The material characterisation was performed using Vickers micro-indentation, differential scanning calorimetry and nano-indentation, whereas functional testing involved mechanical shear tests using single-lap aluminium soldered joints and creep tests. The hardness was observed to improve in all cases except for the 0.01 wt. \% graphene reinforced solders, with 5\% and 4\% improvements in 0.05 carbon black and SWCNT reinforced solders, respectively. The maximum creep indentation was noted to improve for all solder categories with maximum $11 \%$ and $8 \%$ improvements in $0.05 \mathrm{wt} . \%$ carbon black and SWCNT reinforced ones. In general, the $0.05 \mathrm{wt} . \%$ nanomaterial reinforced solders promoted progressive cohesion failure in the joints as opposed to instantaneous fully de-bonded failure observed in pristine soldered joints, which suggests potential application in high-performance structures where no service load induced adhesion failure is permissible (e.g. aerospace assemblies). The novel innovation developed here will pave the way to achieving high-performance solder joining without carrying out extensive surface preparations.
\end{abstract}

Keywords Carbon black $\cdot$ Graphene $\cdot$ Single-walled carbon nanotubes $\cdot$ Tin solder $\cdot$ Single-lap joint

\section{Introduction}

In the current era of lightweight hybrid structures, design, and manufacturing for aerospace and automotive applications, fastener-less high-quality and high-strength

Marek Burda

mb@cametics.com

Saurav Goel

goels@1sbu.ac.uk

$\triangle$ Hamed Yazdani Nezhad

hamed.yazdani@city.ac.uk

1 School of Aerospace, Transport and Manufacturing, Cranfield University, Bedford MK43 0AL, UK

2 Brunel Centre for Advanced Solidification Technology (BCAST), Brunel University, London, UK

3 Cametics Ltd., Unit 24, South Cambridge Business Park, Babraham Road, Sawston, Cambridge CB22 3JH, UK joining methods capable of joining dissimilar materials are being rigorously researched. The main methods used for structural joining are mechanical fastening, adhesive bonding, and high-temperature joining such as welding, brazing, and soldering [1-4]. For joining of dissimilar

4 School of Engineering, London South Bank University, London SE10AA, UK

5 Indian Institute of Technology Guwahati, Guwahati 781039, India

6 University of Petroleum and Energy Studies, Dehradun 248007, India

7 Naval Architecture, Ocean and Marine Engineering Department, University of Strathclyde, Glasgow G1 1XQ, UK

8 Department of Mechanical Engineering and Aeronautics, City, University of London, London EC1V OHB, UK 
materials, adhesive bonding is considered superior to bolted joints as it produces a continuous connection and hence smooth strain transition which greatly reduces stress concentration to benefit the fatigue performance of joints [5]. Although adhesive bonding is similar to brazing and soldering in the sense that the surfaces being joined are energised (e.g. via heating, chemical treatment, or ultra-violet radiations), the bonding formed during adhesive joining (so-called secondary bonding) is not a metallurgical bond; rather, it is a chemical bond (i.e. Van der Waals bond) [6]. However, the polymer bonding poses problems in curing time, inspection, disassembly, and environmental degradation [7-12], as well as the challenge to assure bond quality [13, 14].

Joining aluminium for structural applications has proven to be challenging using traditional welding and brazing practices due to its high coefficient of thermal expansion (CTE). The thermally induced residual stresses at the interface lead to excessive strains causing CTE mismatch between the substrate and the joining material [15]. Whilst other fastener-less technologies such as adhesive bonding, welding, brazing, and solderbased joining provide an improved joint stiffness and limitedly overcome the problem of stress concentration [1-4]. A solder joint is not usual for high-load applications due to it being brittle and its susceptibility to fail catastrophically. In adhesive bonds, the damage tolerance is mainly facilitated by cohesion failure of the bulk adhesive at the interface.

Soldering is a highly suitable method to join wide variety of materials, ranging from composites to metals such as aluminium to ceramic materials [16]. The procedure of soldering involves applying a melted soldering alloy on the heated surface of materials without requiring extensive surface preparation in contrast to a timeconsuming and sensitive surface treatment approach associated with every adhesive bonding method. Contrarily, during adhesion $[17,18]$, the same procedure would require highly controlled surface treatment and possible process-induced tight disbond. Similar to adhesive bonding, the main parameter affecting the solder joint is the wettability, which in turn influences the interfacial strength of the soldered joint that is characterised using techniques such as the single-lap joint shear test [12].

Traditionally, tin (Sn)-based solders are being used as an interconnection material for electronic devices as they are thermally conductive, light weight, do not account for any significant volume increase for the applications, and their mechanical properties do not qualify for high loading applications [19]. However, in recent years, the development of graphene and carbon nanotubes (CNTs) $[10,11]$ has surfaced the idea of embedding carbon nanomaterials into the metal matrices which has opened newer avenues for material joining. It allows to obtain enhanced specific stiffness, strength, wear resistance, controlled CTE, fatigue resistance, and electrical conductivity. The nanomaterial reinforcements are also referred to as metal matrix nanocomposites [20]. Taking these ideas forward, this work hypothesised that the mechanical properties of tin solder could also be tailored and enhanced to withstand high structural loads and temperatures, specifically for joints susceptible to interfacial adhesion failure.

Moreover, the addition of transition metal to solder alloys has also been shown to enhance the wetting of carbon materials at low temperatures, thus enabling dissimilar material joining at low temperature. For instance, the addition of 2.5 to 5.0 wt. \% of $\mathrm{Cr}$ or Ni to $\mathrm{Sn}-3.6 \mathrm{Ag}-0.7 \mathrm{Cu}$ alloys (SAC alloys) showed enhanced wetting and joining of carbon nanotubes (CNTs) [21]. That is mainly due to the uniform nonreactive dispersion of the transition metals in the SAC matrix, which diffuses into the carbon alloy border with no formation of brazing-like carbides.

C-Solder® is a commercial tin-based lead-free low-temperature soldering alloy manufacture by Cametics Ltd. It enables joining of various carbon materials including carbon fibres or CNT fibres in both carbon-carbon and carbon-metal arrangements [22]. During soldering, oxides form on the surface of the molten solder prevents it from wetting the substrate. For that reason, forced wetting or mechanical activation is applied by brushing/peening and ultrasonic agitation in the utilisation of C-Solder ${ }^{\circledR}$.

This research investigated the influence of reinforcing carbon nanomaterials (carbon black (CB), graphene, and singlewalled CNT (SWCNT)) to the C-Solder ${ }^{\circledR}$ [18]. The study includes a comprehensive analysis of data from microstructural characterisation, thermal analysis and mechanical shear performance of soldered joints utilising the pristine solder, and carbon nanomaterial reinforced solder with 0.01 and 0.05 wt.\% loading contents. The joint strength was evaluated using standard single-lap soldered joints made of aerospace-grade aluminium substrates, and under quasi-static loading conditions $[12,23]$.

\section{Materials and methods}

\subsection{Materials}

The samples examined in this research are listed in Table 1, categorised into as-received C-Solder® (CS), solder mixed with carbon black (CB at 0.01 and $0.05 \mathrm{wt} . \%$ content), graphene with 0.01 and 0.05 wt.\% (G_0.01 and G_0.05, respectively), and SWCNTs with 0.01 and $0.05 \mathrm{wt} . \%$. The samples were characterised (i.e. melting temperature via differential scanning calorimetry, Vickers hardness and creep behaviour 
via nano-indentation and via optical and scanning electron microscopy, SEM). The nanomaterials were supplied as follows:

- SWCNT 755,710-1G supplied by Sigma Aldrich (average diameter of $0.84 \mathrm{~nm}$ ),

- Graphene CamGraph® G3 supplied by Cambridge Nanosystems (lateral size of $\sim 400 \mathrm{~nm}$ and flake thickness of $\sim 3 \mathrm{~nm}$ ),

- Carbon black, MONARCH® 800 supplied by Cabot (average diameter of $20 \mathrm{~nm}$ ).

The material preparation process entails mixing of C-Solder ingots with carbon material which were initially loaded into vacuum induction melting furnace. They were mixed via induction stirring in the temperature range of $1000-1200{ }^{\circ} \mathrm{C}$, and casted in vacuum at $1200^{\circ} \mathrm{C}$.

The as-received solder (no nanomaterial addition) was used as a control sample to test the integrity of C-solder®based single-lap soldered joints. High-performance, aerospace-grade Al6082T6 aluminium alloys (tensile strength of $310 \mathrm{MPa}$ and elongation at breakage of $\sim 8 \%$ ) [19] were used as substrate materials for the lap joining.

\subsection{Characterisation of solder materials}

To analyse the dispersion quality of the nanomaterials in the solder samples, the samples were mounted in standard mounting epoxy resin, ground in three stages (using 240, 1200, and 2500 grit papers, each at $200 \mathrm{rpm}$ for $3 \mathrm{~min}$ ), and polished in two stages, each at $250 \mathrm{rpm}$ for $4 \mathrm{~min}$ (using plano cloth drenched with $3-\mu \mathrm{m}$ diamond suspension followed by OP-S Colloidal Silica). SEM-EDS analysis was conducted to identify the composition and their dispersion-distribution quality.

A differential scanning calorimeter (DSC) was used to determine the melting point of the solders. The total weight of the samples cut from solder rods was kept less

Table 1 Solder samples studied and their methods of preparation

\begin{tabular}{ll}
\hline Solder samples & Induction mixed and cast in vacuum at $1200{ }^{\circ} \mathrm{C}$ \\
\hline CS & C-Solder ${ }^{\circledR}$ \\
CB_0.01 & C-Solder ${ }^{\circledR}$ reinforced by $0.01 \mathrm{wt} . \% \mathrm{CB}$ \\
CB_0.05 & C-Solder ${ }^{\circledR}$ reinforced by $0.05 \mathrm{wt} \%$ CB \\
G_0.01 & C-Solder ${ }^{\circledR}$ reinforced by $0.01 \mathrm{wt} \%$ graphene \\
G_0.05 & C-Solder ${ }^{\circledR}$ reinforced by 0.05 wt.\% graphene \\
SWCNT_0.01 & C-Solder ${ }^{\circledR}$ reinforced by 0.01 wt.\% SWCNT \\
SWCNT_0.05 & C-Solder ${ }^{\circledR}$ reinforced by 0.05 wt.\% SWCNT \\
\hline
\end{tabular}

than $10 \mathrm{mg}$. The samples were placed into an aluminium pan which was heated to temperature of $300{ }^{\circ} \mathrm{C}$ with a heating rate of $3{ }^{\circ} \mathrm{C} / \mathrm{min}$.

Hardness testing was conducted using a Vickers microindenter apparatus (ZwickRoell ZHV). Using Vickers, three indentations were applied along each solder sample with a load of 25 gfor $15 \mathrm{~s}$. The creep behaviour of the solders under nano-indentation loads was evaluated using a nano-indenter with a Berkovich tip, shown schematically in Fig. 1.

Six indentations per sample were made with spacings of $35 \mu \mathrm{m}$ between consecutive indentations. Load controlled testing during the nanoindentations with a minimum and maximum constantly held loads of $20 \mathrm{mN}$ and $100 \mathrm{mN}$, respectively, were used in the test scheme. The loading rate was $1 \mathrm{mN} / \mathrm{s}$ and the holding time was $120 \mathrm{~s}$. When the load reached maximum value, the indentation depth versus time was recorded and used for the creep performance evaluation, schematically shown in the inset in Fig. 1.

The creep response was evaluated using a power-law creep equation over a wide range of strain rates known as the secondary or steady-state creep regime under constant loads [24, 25]. Thus, assuming a constant temperature and steady-state creep, the creep strain rate $(\dot{\varepsilon})$ can be expressed as [26]

$\dot{\varepsilon}=B\left(\frac{\sigma}{G}\right)^{n}$,

where $B$ is a material constant, $n$ is the stress exponent, $G$ is the temperature-dependent shear modulus, and $\sigma$ is the applied stress.

The temperature dependence of the shear modulus of pristine Sn has been adopted in this study, in which $\mathrm{G}$ can be empirically calculated from [27]

$G=16,302-40.5(T-273)$,

where $T$ is the temperature in Kelvin. $\dot{\varepsilon}$ and $\sigma$ can therefore be expressed by $[28,29]$

$\dot{\varepsilon}=\frac{1}{h} \frac{d h}{d t}$

and

$\sigma=\frac{P}{A}$,

where

$A=24.5 h^{2}$,

and $h$ is the depth of indentation, $t$ is the creep time, and $P$ is the indentation load. Finally, using Eqs. (1)-(5), the creep stress exponent can be calculated: 
Fig. 1 Schematic illustration of creep test using nano-indentation with a Berkovich indenter

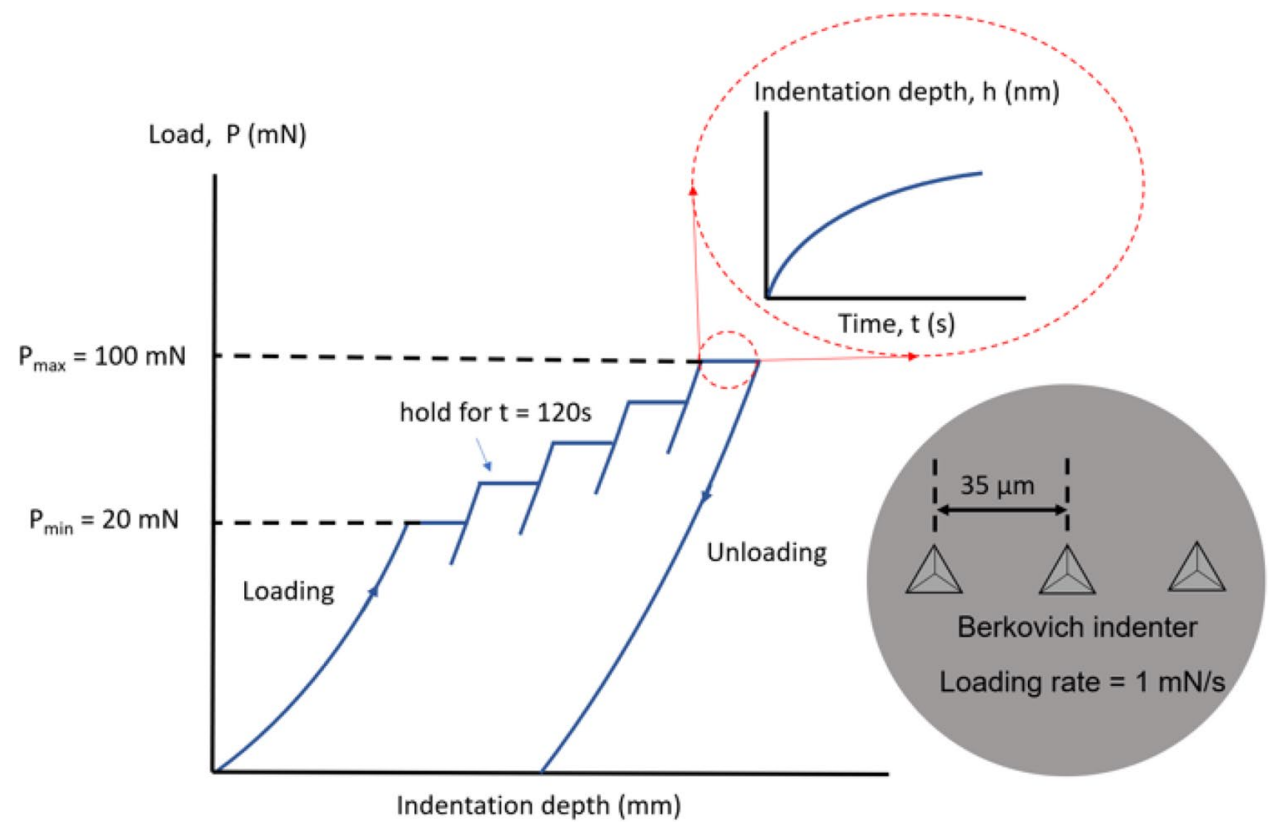

$n=\partial \operatorname{Ln} \dot{\varepsilon} / \partial \operatorname{Ln}(\sigma / G)$

\subsection{Joint evaluation}

\subsubsection{The joining process}

The Al6082T6 specimens were joined using C-solder $®$ and its nanomaterial reinforced variations (four specimens per variation) with the dimensions (according to Standard ASTM D1002 specimens) shown in Fig. 2.

The aluminium substrates (laps) were pre-heated on a ceramic hot plate (Stuart $\mathrm{CN} 302$ ) at $350{ }^{\circ} \mathrm{C}$. The solder was deposited on the laps using a SUNBONDER USM-560 ultrasonic soldering iron at a temperature of $400{ }^{\circ} \mathrm{C}$ (the specified optimal wetting temperature for C-Solder () , an ultrasonic power of $10 \mathrm{~W}$, and at an ultrasonic-frequency of $65 \mathrm{kHz}$. The lap joints were then pressed and left on the hot plate to cool down (Fig. 3) using steel press bars. The pressure fixture shown in Fig. 3 was formerly designed and assembled for research on single-lap bonded joints $[17,18]$ in compliance with the ASTM D1002. The thickness of the solder was controlled by using aluminium laps of thickness $3.4 \mathrm{~mm}$ to even out the laps of the specimens (so that no misalignment occurs during clamping in the gripping areas), and allow a solder thickness of $0.2 \mathrm{~mm}$. After the joining process, a two-component Araldite $420 \mathrm{~A} / \mathrm{B}$ epoxy adhesive was used to bond the aluminium tabs at the ends of the specimens, followed by curing in an oven at $70{ }^{\circ} \mathrm{C}$
Fig. 2 The dimensions of the A16082T6 single-lap shear soldered joint specimens

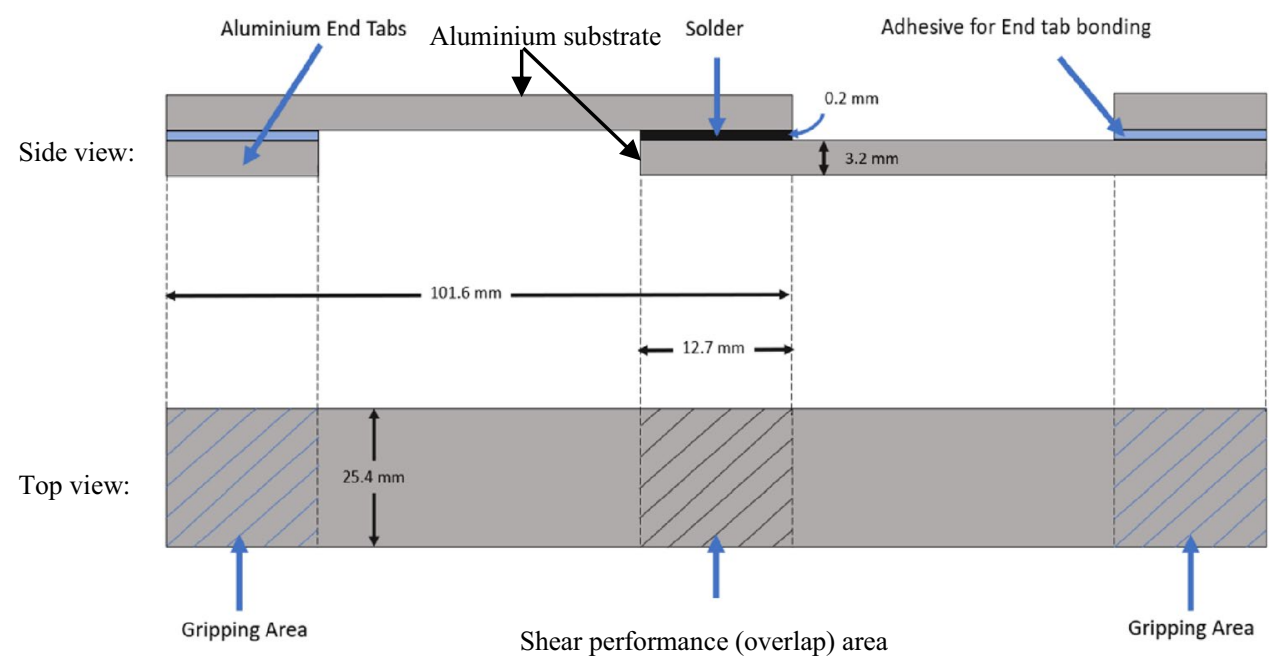


Fig. 3 Aluminium laps joining process: (1) fixing aluminium lower laps, (2) apply the solder material, (3) fix upper aluminium laps, and (4) apply uniform pressure
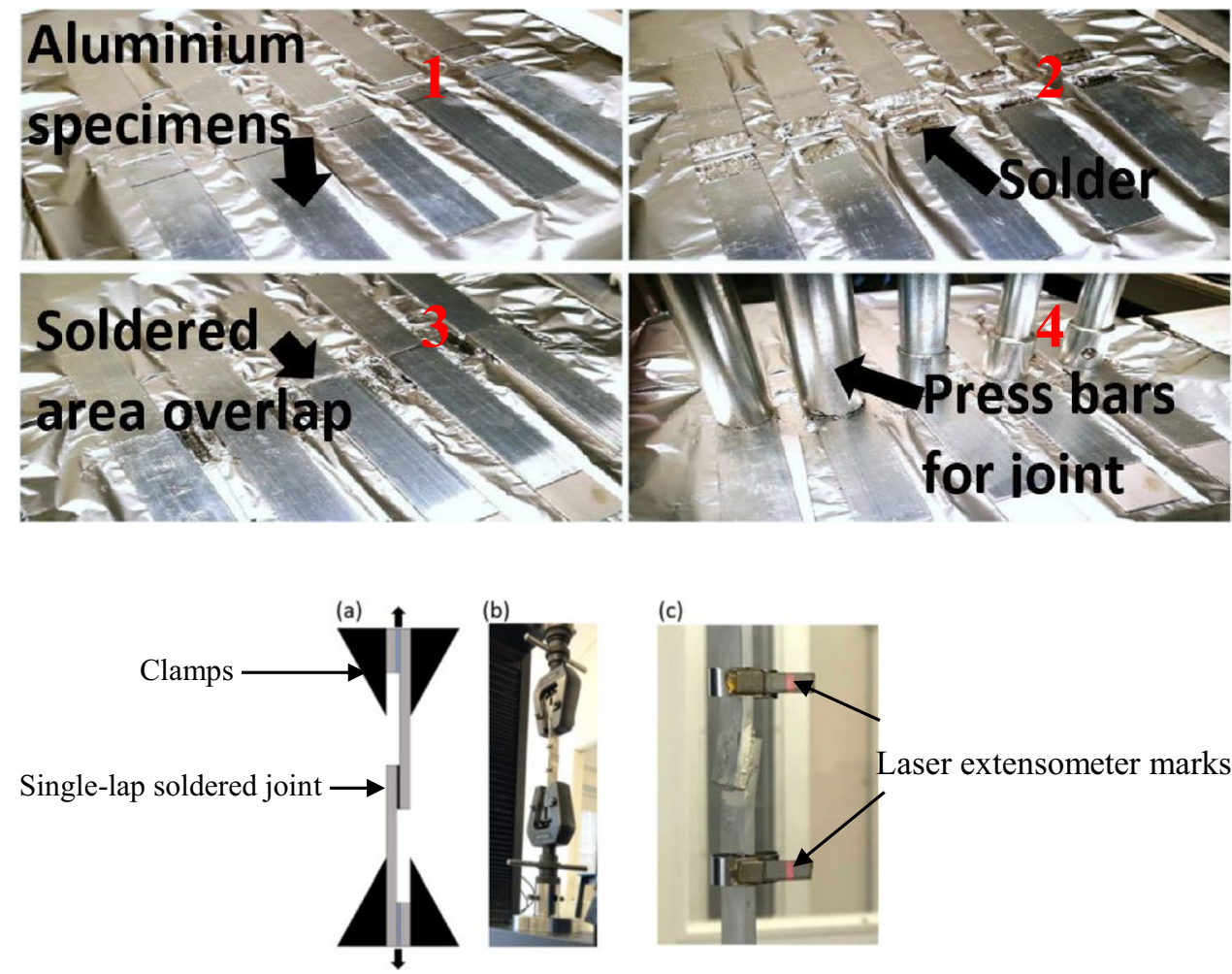

Fig. 4 (a) Schematic of fixed lap shear test apparatus, (b) soldered aluminium sample under tensile loading, and (c) marks for laser extensometer (displacement) measurements local to the soldered overlap

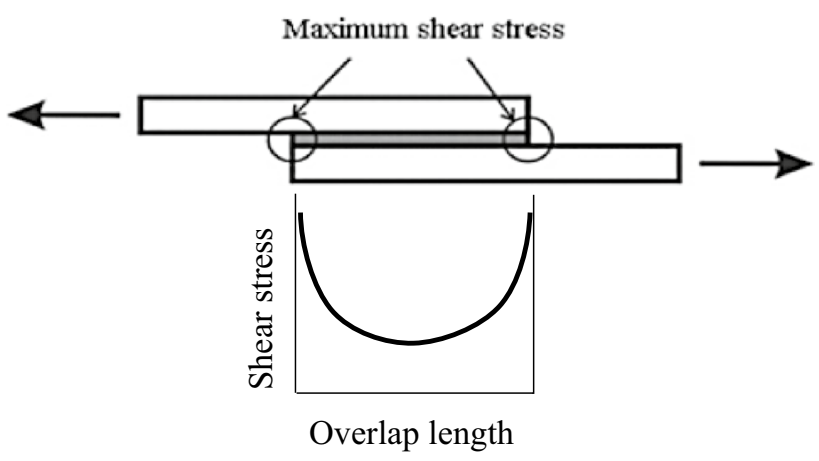

Fig. 5 Schematic illustration of shear stress distribution in an adhesively bonded joint [30]

maximum shear stress occurring at the two ends of the joint [30] shown schematically in Fig. 5. Therefore, the joint shear and failure performance have been described based on the load and displacement data for the localised areas, and the average stress-strain calculations have been used to describe creep using the equations discussed above.

Failure of the joint was predicted to initiate at the edges first, when the effective stress exceeds the yield strength of the joint. Adams et al. (1997) [26] showed that the strength of the adhesive joint increases linearly with longer overlap length, until a certain threshold beyond which no stronger bonds are formed [31]. It occurs after the threshold plastic deformation of the aluminium substrate becomes dominant (soldered here) can be highly non-uniform $[17,18]$ with the

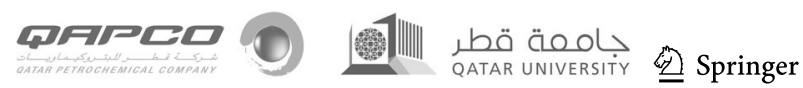


which induces bond failure. This has been further discussed in the next sections. The mode of failure was microscopically investigated by observing the shear area after lap shear test using an Oxford Instrument SEM and a Nikon Eclipse Me600 optical microscope.

\section{Results}

\subsection{Solder characterisation}

\subsubsection{Microstructural analysis}

The typical microscopic images for the induction mixed solders with and without the carbon nanomaterials are presented in Fig. 6. The identification of carbon nanomaterials was not conducted in the optical microscopy images, and therefore not shown in the scale presented in these images. Instead, the agglomerated cluster particles were observed as dark regions within the solder medium. The figure mainly shows such particle arrangements. It may be noteworthy that the two other mixing methods were also tested but the one shown here provided the best practice for achieving better dispersion. Typical SEM-EDS analysis of the reference solder's microstructure (no nanomaterial addition) resulted in the composition shown in Fig. 7, showing $\mathrm{Sn}, \mathrm{Cr}, \mathrm{Ag}_{3} \mathrm{Sn}$, and $\mathrm{Sn}_{5} \mathrm{Cu}_{6}$.

\subsubsection{Thermal analysis}

Figure 8 shows the DSC profile of C-Solder ${ }^{\circledR}$ and its nanomaterial reinforced variations. A distinctive single endothermic peak was observed with the onset temperature in all materials, defined as the starting temperature for endothermic reaction, between $218.09^{\circ} \mathrm{C}$ and $219.749^{\circ} \mathrm{C}$, and the melting temperature in the range of 219.99 to $222.68{ }^{\circ} \mathrm{C}$.

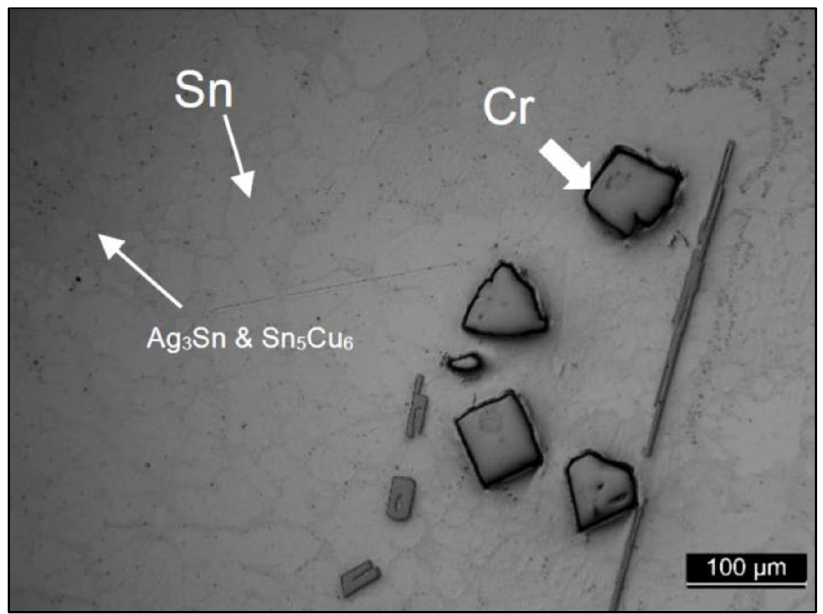

Fig. 7 Typical composition of the reference solder material with no nanomaterial addition obtained from the EDS analysis, dominantly present by Tin ( $\mathrm{Sn}), \mathrm{Cr}, \mathrm{Ag}_{3} \mathrm{Sn}$, and $\mathrm{Sn}_{5} \mathrm{Cu}_{6}$
Fig. 6 Typical SEM micrographs of C-Solder® sample induction mixed with carbon nanomaterial via identical mixing parameters (captured at $5 \mathrm{kV}$ ): (a) pristine solder, (b) 0.05 wt.\% CB reinforced solder, (c) 0.05 wt. \% graphene reinforced solder, and (d) 0.05 wt.\% graphene reinforced solder
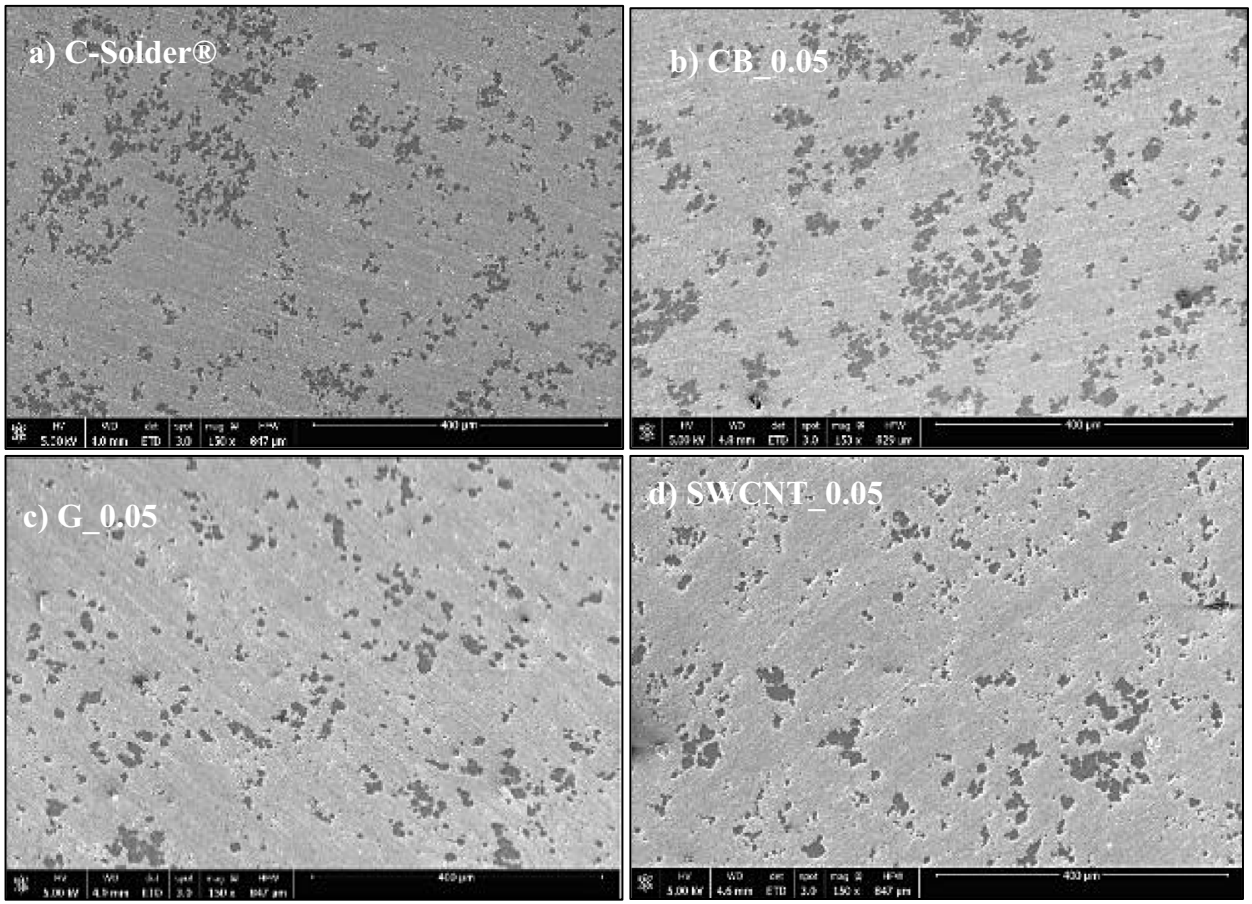
As can be seen from Fig. 9, the change in the melting temperature between the samples was not significant but a slight reduction in the melting temperature was observed for the G_0.01 $\left(219.99{ }^{\circ} \mathrm{C}\right)$ whereas an increase for the SWCNT_0.05 (222.68 $\left.{ }^{\circ} \mathrm{C}\right)$ [23].

In comparison with conventional lead-free solders such as the $\mathrm{Sn}-3.5 \mathrm{Ag}$, the melting temperatures were slightly different [32]. This behaviour is consistent with the studies conducted on the addition of Ni-CNTs to $\mathrm{Sn}-\mathrm{Ag}-\mathrm{Cu}$ solder alloy $[20,21]$ and the observations on the addition of carbon black to Sn-3.5Ag [32]. Since the temperatures required to melt these reinforced solders are very low relative to melting temperatures of joining substrates (aluminium), it can be emphasised that the thermal stresses induced in the substrates, during the joining process, were minimal.

\subsubsection{Vickers hardness}

The hardness improvement after addition of nanomaterials into metal matrix has been reported to arise from either of the four main mechanisms [33]:

- Load transfer strengthening;

- Dislocation bowing or dislocation interference (a.k.a. Orowan strengthening);
Fig. 8 DSC profiles for (a) C-Solder ${ }^{\circledR}$ (no nanomaterial addition), (b) $0.01 \mathrm{wt} \%$ carbon black reinforced solder, (c) 0.05 wt. \% carbon black reinforced solder, (d) $0.01 \mathrm{wt} . \%$ graphene nanoparticle reinforced solder, (e) $0.05 \mathrm{wt} . \%$ graphene nanoparticle reinforced solder, $(\mathbf{f})$ $0.01 \mathrm{wt} . \%$ SWCNT reinforced solder, and (g) 0.05 wt.\% SWCNT reinforced solder
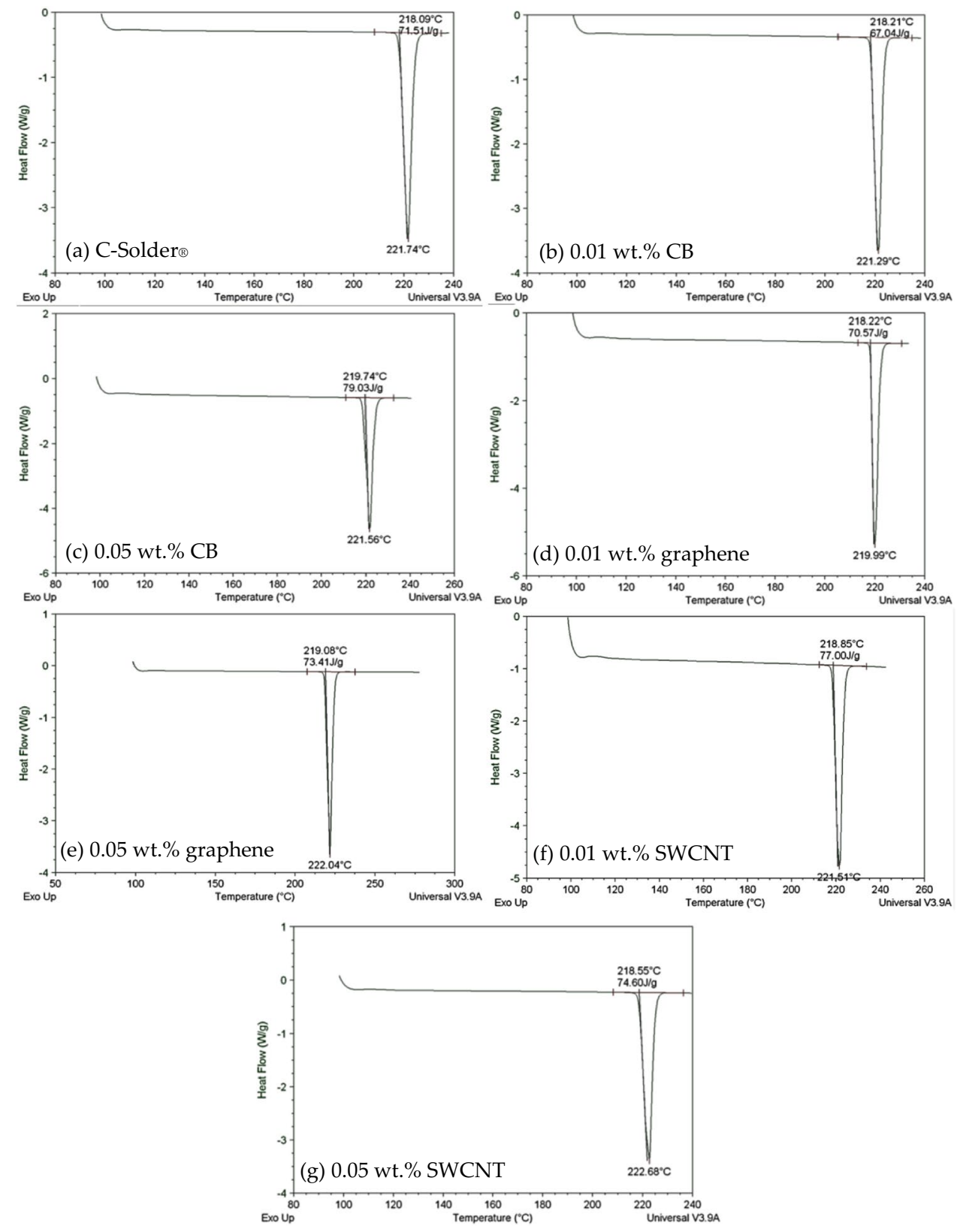


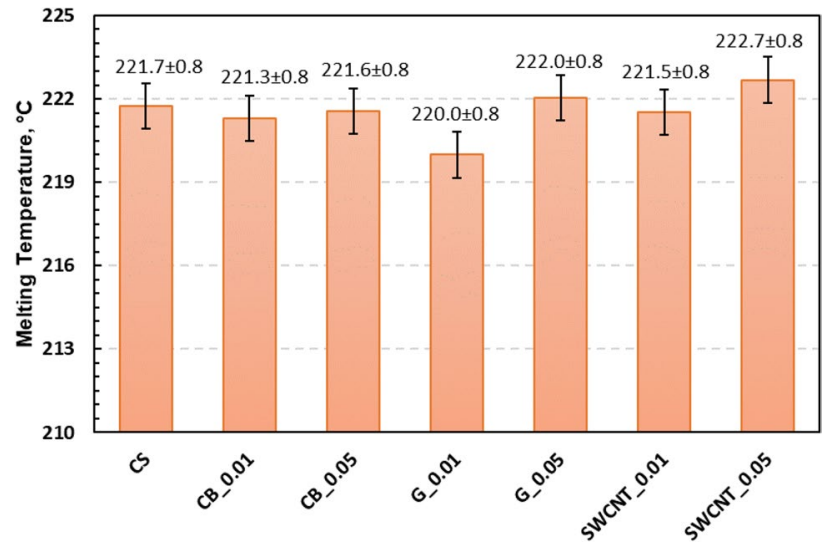

Fig. 9 Melting temperature of the solder with and without mixing of nanomaterials

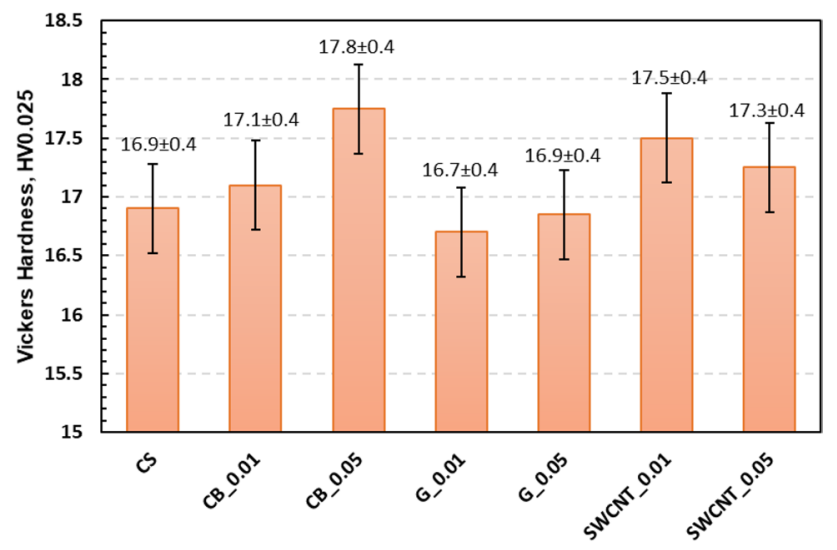

Fig. 10 Vickers hardness of solders with different compositions

- Strengthening due to thermal, elastic moduli, or geometric mismatch between nanofiller and metal matrix; and

- Grain improvement strengthening

Slight increase was observed in the transition from the as-received C-Solder® to $0.01 \mathrm{wt} . \% \mathrm{CB}$, and a significant increase in 0.05 wt.\% CB enhanced C-Solder ${ }^{\circledR}$ (Fig. 10) by nearly $0.85 \mathrm{HV}$. The increase was also seen in the case of SWCNT addition at $0.01 \mathrm{wt} . \%$ and $0.05 \mathrm{wt} . \%$, however lower at 0.05 wt.\% SWCNT, attributed to the extensive agglomeration shown in Fig. 6(g), compared to that of the 0.01 wt.\% sample observed to attain a more uniform SWCNT dispersion in Fig. 6(f). The hardness of G_0.01 was found lower than that of the C-solder ${ }^{\circledR}$ by maximum $0.2 \mathrm{HV}$, and G_0.05 approximately the same as the pristine solder. It is not clear whether the slight downfall in the G_0.01 material is due to the morphological changes in graphene nano-platelet (as opposed to spherical cluster formed in the CB and SWCNT cases) or is attributed to a weak bonding between the nanomaterials and the solder matrix. Figure 6(b), (d) show similar dispersion quality for $\mathrm{G} \_0.01$ and $C B \_0.01$, whilst CB_0.01 presents a slightly more uniform distribution. On the other hand, Fig. 6(f) presents SWCNT_0.01 in better dispersion and distribution than the other two. This suggests that the distribution quality may have played a role (though not quantified). A definite statement based upon morphological changes or distribution effects would be forfuitious, and would require further investigations. Therefore, further investigations were carried out in Sect. 3.1.4 where the nanoindentation data and its scatter are discussed.

Nevertheless, as a comparative remark, in comparison to other solders like the Sn-3.5Ag and SAC305 (HV $\approx 14-15$ ), C-Solder ${ }^{\circledR}$ in Fig. 10 showed a higher hardness value [23, 34], mainly due to the presence of chromium in the solder matrix which restricts dislocation motion [35]. This restriction can be overcome by addition of carbon nanomaterials according to our phenomenological study above, i.e. the promotion of dislocations restriction but with carbon nanomaterials mimicking chromium role.

\subsubsection{Creep behaviour during nano-indentation}

Typical indentation load vs. depth curve for the C-Solder® samples conducted at room temperature under maximum load of $100 \mathrm{mN}$ is presented in Fig. 11. Following Fig. 11, five loading/unloading nano-indentation cycles were performed for all samples:

$\mathrm{ABCD}$ points on the curve represent the first loading/ unloading cycle. $\mathrm{AB}$ represents the first loading process, $\mathrm{BC}$ the constant load holding process, and $\mathrm{CD}$ on the curve represents the unloading process. FG shows the change in the indentation depth, held for $120 \mathrm{~s}$ when the maximum load of $100 \mathrm{mN}$ is reached and was held constant. Creep is operative during this holding time and was extracted from further analysis (results shown in Figs. 12 and 13). The solder samples exhibited significant permanent (inelastic) deformation and slight elastic recovery, as apparent from the unloading curve (GH). No discontinuities were observed on the curves which indicated that no fracture occurred during the indentation tests [36].

Figure 12 compares the average indentation depth for all samples at the maximum load $(100 \mathrm{mN})$. As seen, all reinforced solders exhibit increased indentation depth under creep conditions, with 0.05 wt.\% nanomaterial reinforced solders (CB_0.05, G_0.05, and SWCNT_0.05) exhibiting the highest creep indentation compared to their $0.01 \mathrm{wt} . \%$ companions, with G_0.01 showing the largest scatter. Therefore, creep deformation under constant load was higher in solders with higher contents, indicative of promoting deformation mechanisms enabled by higher nanomaterial content which increases the strain energy dissipation via provision of relatively higher contact areas between the nanomaterials and the solder matrix. Such performance was seen to 
Fig. 11 Typical load vs. indentation depth curve for the C-Solder ${ }^{\circledR}$

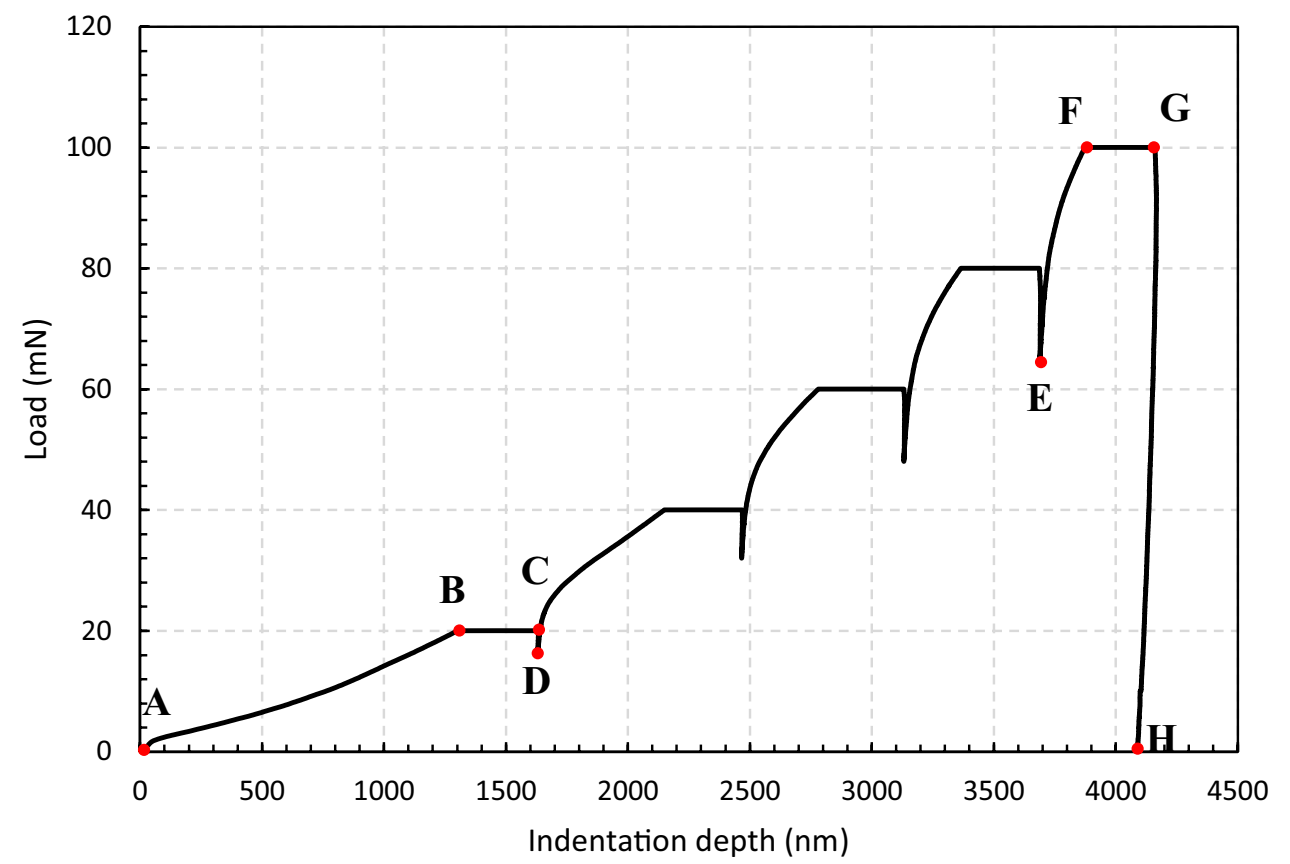



Fig. 12 Average creep nano-indentation depth of solders with and without nanomaterials

improve pristine solder's brittleness towards ductility under constant load creep conditions. Similarly in Fig. 10, the hardness was higher or equal in high-content nanomaterial reinforced solders than low-content ones (with the exception of SWCNT_0.05 due to relatively higher agglomeration and poor distribution). This, together with the creep indentation data, suggests a high-strength material with high creep deformation at high carbon nanomaterial contents. As seen, G_0.01 (the case with the lowest hardness) shows the highest scatter and only a slight creep indentation in Fig. 12. Further analysis requires full investigation throughout the creep regime alongside microscopic images, conducted and described in Fig. 13:
Figure 13 presents the creep indentation depth vs. holding time, averaged between six indentations per sample category (indexed by _1 to _6 in the figure) under constantly held loads. The shaded area between two dashed lines in all sub-figures shows the range of data for the nonreinforced solder (i.e. C-Solder ${ }^{\circledR}$ ). Such area is repeated in all sub-figures in the interest of a comparative analysis. This data is accompanied by microscopic images for each material, taken from Fig. 6. The high disparity in creep performance is due to the non-uniform distribution and dispersion of nanomaterials in the reinforced solders observed in the microscopic images. It is noted that the data on the left column sub-figures are not directly comparable to the images since the indentation was performed at different locations; however, for a clearer size comparison of the positions at which the six-indentation may have occurred compared to the size of the microscopic images presented here, three grid area have been identified on locations with localised high, medium, and low nanomaterial dispersion, identified by $\mathrm{H}, \mathrm{M}$, and $\mathrm{L}$, respectively. Each grid represents the positions in six subsequent elements over which the indentation may have occurred (each element size was spaced by $35 \mu \mathrm{m}$ ). The difference in the creep data in relation to their high scatter/disparity can be investigated from the microscopic images in a using the grid areas and arbitrary selection of one row or column of six-subsequent elements. This simply means that if the six-indentation were performed over the $\mathrm{L}$ regions, the scatter would have been lower than the case that the path is conducted over the $\mathrm{H}$ and $\mathrm{M}$ regions. The reason is that the distribution of nanomaterials in the $\mathrm{L}$ regions over six 



Fig. 13 Indentation depth vs. time at constant loaded creep for (a) $0.01 \mathrm{wt} \% \mathrm{CB}$, (b) $0.05 \mathrm{wt} \% \mathrm{CB},(\mathbf{c}) 0.01 \mathrm{wt} \%$ graphene, (d) 0.05 wt. $\%$ graphene, (e) 0.01 wt. \% SWCNT, and (f) 0.05 wt.\% SWCNT

subsequent elements (representative of the six indentation spacings) is relatively more uniform than that in the $\mathrm{H}$ and $\mathrm{M}$ regions. This assumes that the material immediately underneath the visible surface follows the same pattern on the surface distribution. The analysis is then suggested to follow the concepts of dispersion-distribution 

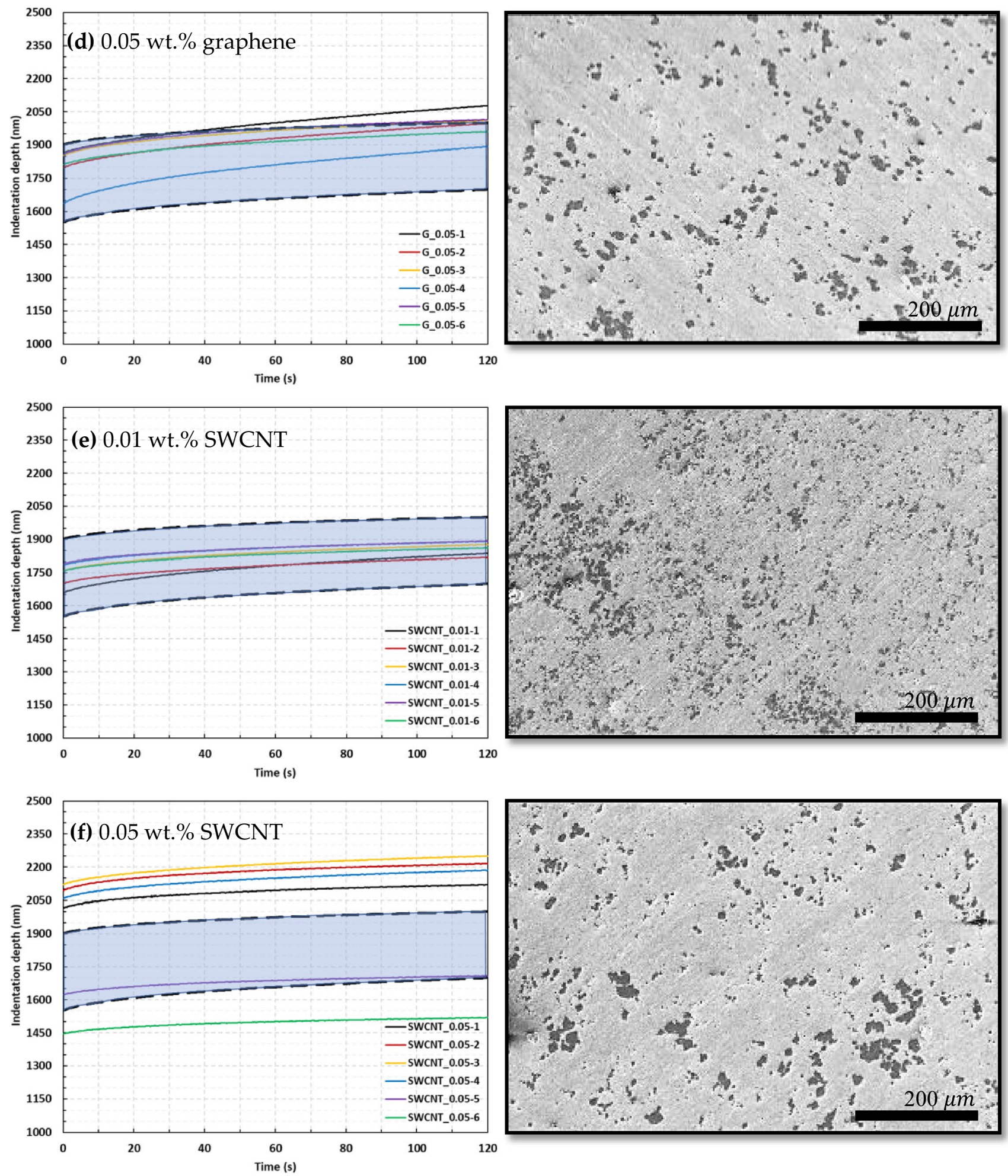

Fig. 13 (continued)

schematically illustrated in Fig. 14. According to the figure, $0.01 \mathrm{wt}$ \% $\mathrm{CB}$ has poor distribution and dispersion of the CBs while 0.05 wt.\% CB showed good distribution while having poor dispersion. Both graphene reinforced solders (0.01 wt.\% and 0.05 wt.\%) are poor in distribution and dispersion, also the case with the $0.05 \mathrm{wt}$. $\%$ SWCNT. The only reinforced solder material with almost both good distribution and dispersion quality is $0.01 \mathrm{wt}$.\% SWCNT 
Typical carbon nanomaterial reinforced solder in

high black \& white contrast

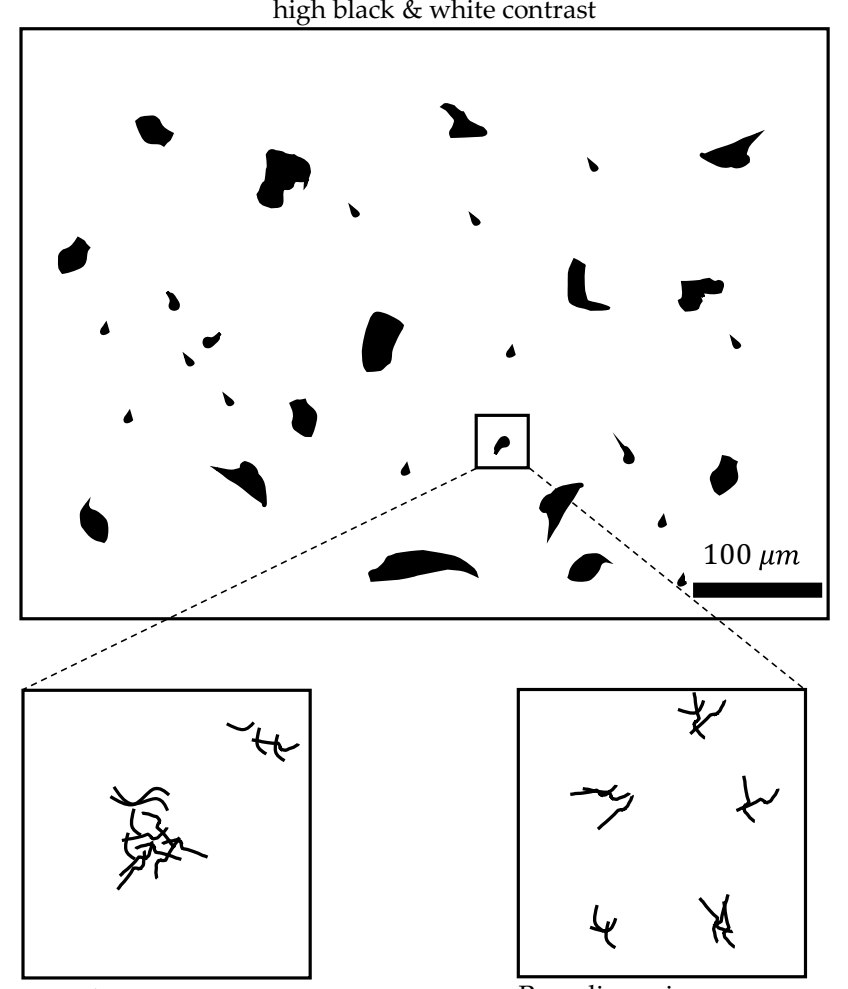

Poor dispersion

Poor distribution



Good dispersion

Poor distribution
Poor dispersion

Good distribution

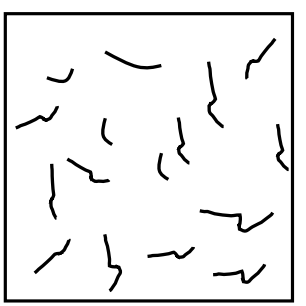

Good dispersion

Good distribution

Fig. 14 Schematic illustration of dispersion and distribution quality

which is the only material with the lowest scatter observed in Fig. 13(e). This suggests the direct link of the scattered data to the distribution-dispersion quality where the nanoindentation data with lowest disparity appears from a nanocomposite with reasonably good dispersion and distribution.

Moreover, the observations for SWCNT_0.05 along with those in Fig. 10 (hardness) and Fig. 12 (creep), and compared to those for SWCNT_0.01, indicated that an addition of $0.05 \mathrm{wt} . \%$ of SWCNT has a deteriorating effect on the hardness but an enhancement in creep performance owing to promoting deformation mechanisms (alternatively increased

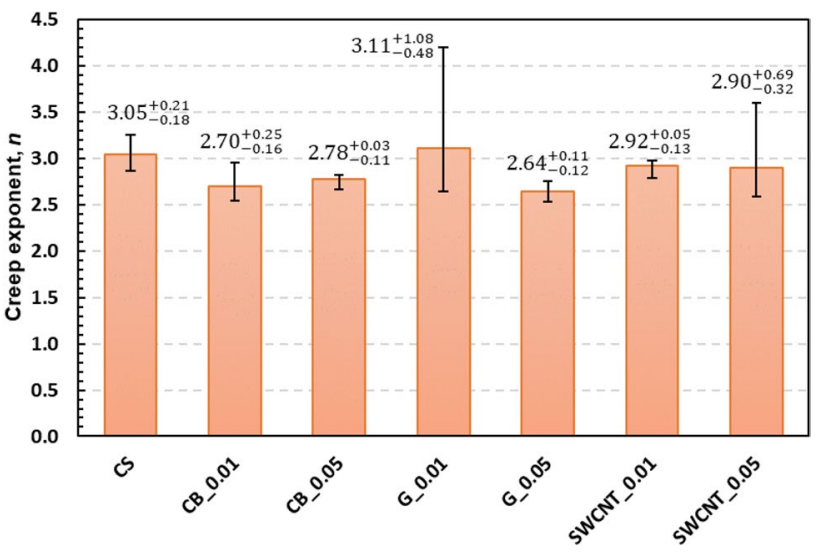

Fig. 15 Creep stress exponents of solder samples

creep rate and strain). Assuming constant solder matrix and process parameters, one may stipulate that the major reason for such performance at high nanomaterial content is due to the morphological changes which upon numerous agglomeration points can induce localised stress concentration [37].

From the slope of the indentation vs. time curves in Fig. 13, the creep stress exponents for the solder materials were calculated using Eq. (6). The results are presented in Fig. 15.

It is common to use the value of the power-law creep stress exponent as an indicator of the rate and mechanism driving the creep deformation in metals. As seen in Fig. 15, the exponent for all solder materials is nearly three, indicating that the main governing deformation mechanism is creep dislocation glide [38] which is common for low-temperature creep deformation mechanism. That partially ratify our former discussion that the addition of carbon nanomaterials mimic the role of chromium in solder material in terms of dislocations enhancement. For G_0.01 and SWCNT_0.05, a high disparity in the exponent data is seen, obtained from fitting the power-law equation (Eq. (1)) to the actual creep data which exhibited the highest scatter, i.e. Fig. 13(c) and (f).

\subsection{Single-lap soldered joint evaluation data}

\subsubsection{Joint quality analysis}

All joints soldered by different material categories were cutsectioned and investigated via optical microscopy, and none showed any void formation owing to the controlled pressurisation and assembly procedure described in Sect. 2.3.1. The voids were inherently present in the materials prior to pressurisation (Fig. 6). Typical optimal images of an aluminium-aluminium soldered joint assembled using G_0.05, CB_0.05, and pristine C-Solder ${ }^{\circledR}$ are shown in Fig. 16. The images for $0.01 \mathrm{wt} . \%$ materials are not shown as they looked 
identical to their $0.05 \mathrm{wt} . \%$ pairs as observed across a large range of the interface. A fully adhered interface by soldering has been observed for the specimens examined, at 0.01 and $0.05 \mathrm{wt} . \%$ except that a slight irregularity is seen in the soldered interface in the CB_0.05 specimen. Though such observation can be made for all specimens depending on the magnified areas (i.e. further magnification than that presented in the figure can lead to the observation of more irregularities in the specimens), the authors could identify relatively more numbers in a $1-\mathrm{mm}$ area in the $\mathrm{CB} \_0.05$ interface, hence providing a comparative analysis together with the mechanical shear performance.

\subsubsection{Single-lap joint testing}

The shear load vs. displacement data for all soldered joints are shown in Fig. 17. Two single-lap joint specimens per nanomaterial type have been presented in the interests of clarity, representing the weakest and highest ductile performance (lowest and highest failure strain exhibited, respectively) of the joints in each category. The results of the joints made of the pristine solder are shown in solid lines. The data with the $0.01 \mathrm{wt} . \%$ nanomaterial content (Fig. 17a) show a load-displacement performance falling between the weakest and strongest pristine soldered joints. However, the scatter in load-displacement data for the
Fig. 16 Typical optical microscopic images for aluminium joint interface with (a) C-Solder ${ }^{\circledR},(\mathbf{b}) 0.05$ wt.\% CB reinforced solder, and (c) 0.05 wt.\% graphene reinforced solder
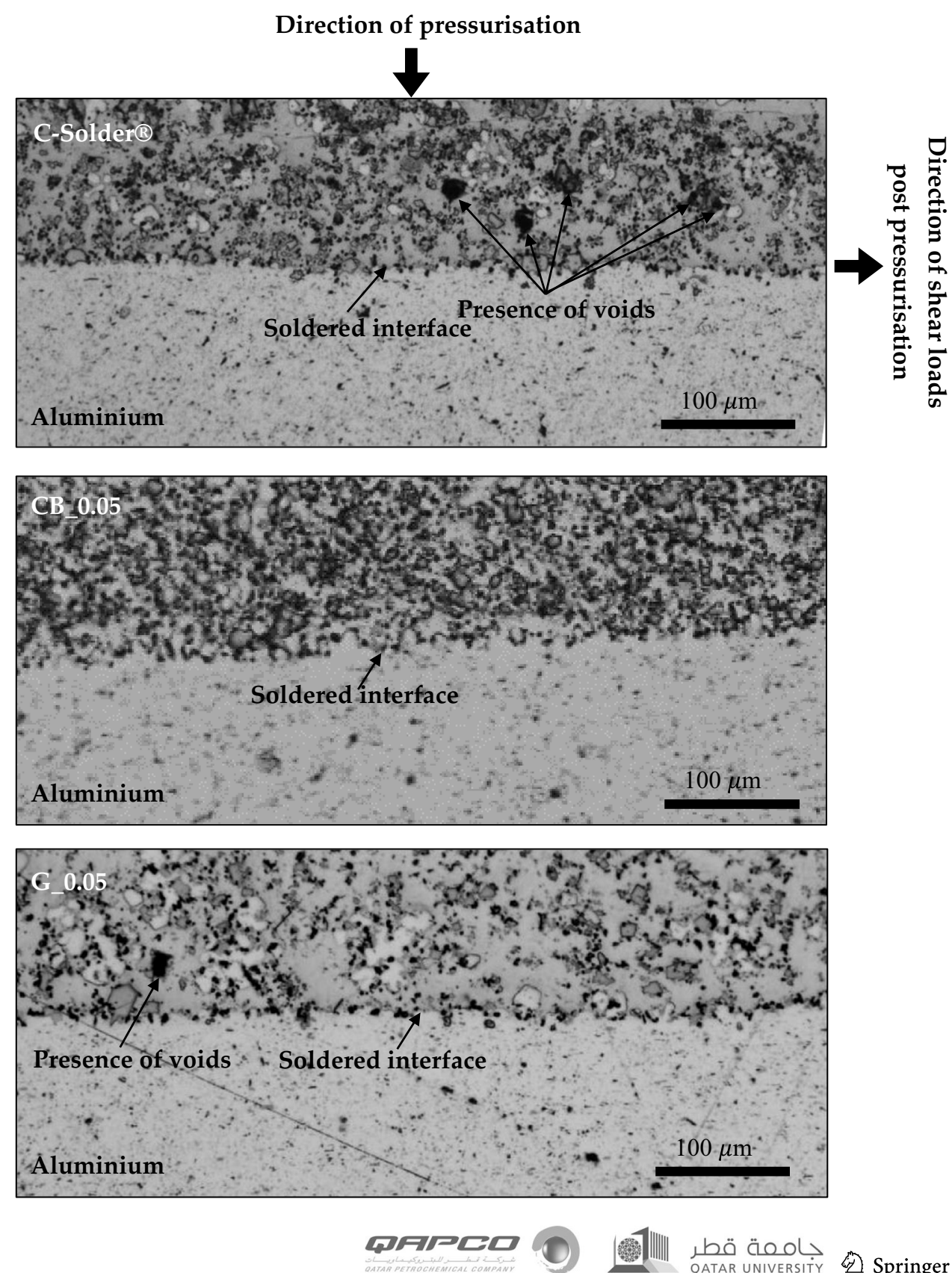
Fig. 17 Shear load versus displacement data in single-lap joints soldered by pristine and nanomaterial reinforced solders:

(a) comparison of pristine solder joint performance with $0.01 \mathrm{wt}$ \% carbon nanomaterial content and (b) comparison of pristine solder joint performance with 0.05 wt. $\%$ carbon nanomaterial content
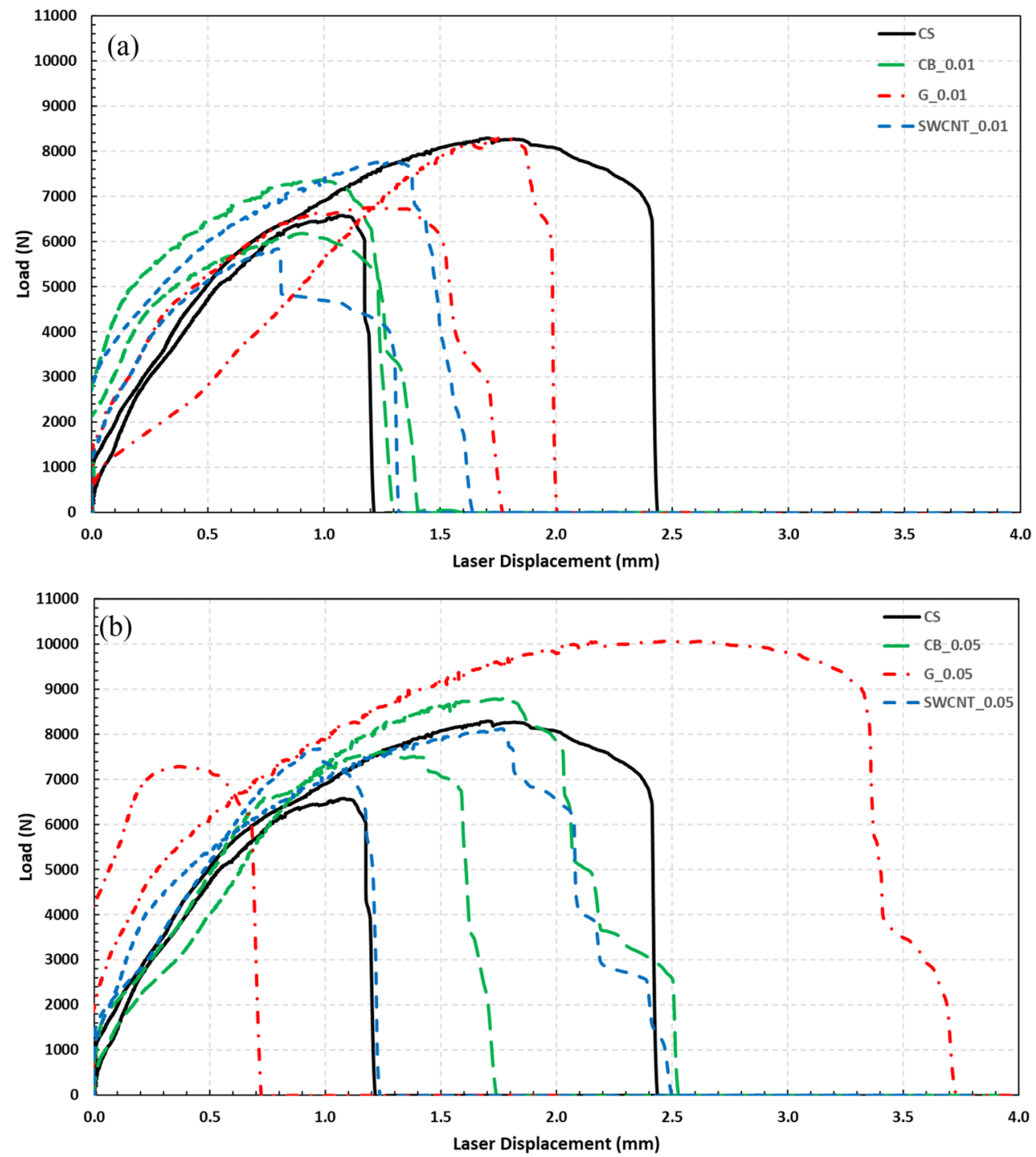

reinforced soldered joints is lower than that of the pristine joint. The SWCNT_0.01 and CB_0.01 showed weaker performance than the G_0.01 in terms of the highest load reached and the ultimate displacement at failure. Recalling from Figs. 10 and 12, G_0.01 possessed the lowest hardness and creep indentation depth, while it performs better than the other $0.01 \mathrm{wt} \%$ carbon types in the joints herein. This is due to either introduction of a better bonding quality with aluminium or pressurisation during development of the soldered joints, or both. No research has particularly studied the bonding quality of graphene nanomaterial with aluminium or aluminium oxide; however, a number of articles have investigated the effect of graphene addition to aluminium in metal matrix composites (MMC) [39, 40].

On strength, stiffness, and hardness in numerous graphene types, processes, and contents, up to nearly $200 \%$, $80 \%$, and $30 \%$ in tensile strength, stiffness, and toughness are reported, comparable to those of the CNT addition in aluminium-based MMC. Therefore, a direct conclusion cannot be reliably drawn. Further investigation is required with focus on the bonding quality of such joints examined here.

The aluminium joints soldered by the $0.05 \mathrm{wt} . \%$ carbon nanomaterial reinforced solder materials (Fig. 17b) also exhibit a superior performance in case of graphene in the ultimate failure displacement and the peak load reached. The other 0.05 wt.\% reinforced types also performed better from their $0.01 \mathrm{wt} . \%$ cases.

The failure load in almost all joints soldered by $0.01 \mathrm{wt} . \%$ reinforced solders was lower than the pristine solder. This can be attributed to the fact that in some areas in the solder matrix, the carbon nanomaterials coming into contact with each other form clusters due to strong Van der Waals forces between them $[23,25]$. This may hinder the bonding between the nanomaterials and the solder matrix which in turn results in cluster induced porosity that act as potential stress concentration site and promote joint failure. However, when the weight percentage of nanomaterials increases from 0.01 to 0.05 wt. $\%$, the failure load generally increases. Despite the 
Fig. 18 (a) Failure of Al6082T6 joint during lap shear testing and (b) schematic illustration of eccentricity and peel stress driven bending in single-lap joints



(a)

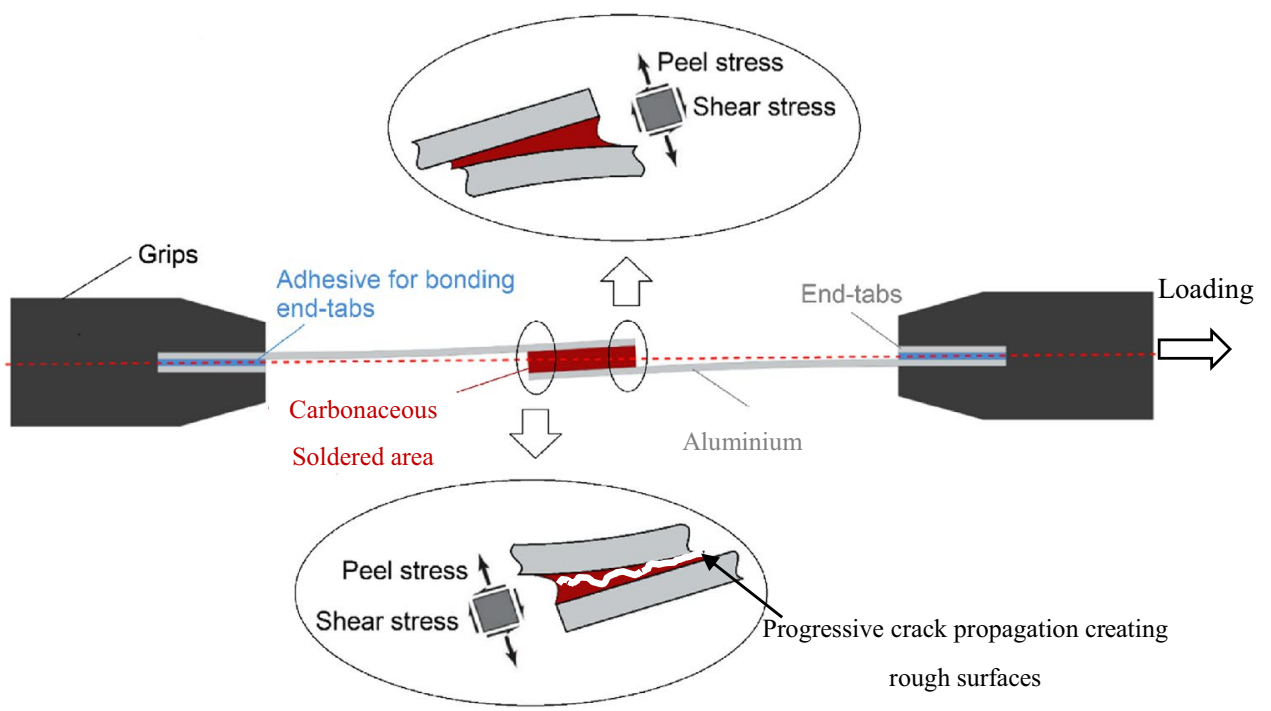

(b) ongoing agglomeration there remains sufficient nanomaterial to develop bonding with the matrix. This is speculative based on the phenomenological data presented in Fig. 17(b) but is in contrast to the existing literature which reported that microscopic level porosity starts to affect the strength of the solder with the addition of more than $0.05 \mathrm{wt} . \%$ of carbon nanomaterials [41]. Considering the discontinuity in the failure load pattern pinpointed in SWCNT_0.01 and the fact that all SWCNT_0.01 joints utilised solder from the same ingot, solder quality issues might be addressed because of the contamination of the solder, i.e. excessive solder oxidation.

Moreover, the failure loads and shear strengths of soldered joints are comparable to adhesively bonded aluminium joints. According to a study [42], the maximum lap shear load withstood by an ARALDITE Rapid epoxy-based adhesive mixed with aluminium powder/aluminium joint was approximately $3.7 \mathrm{kN}$ and the corresponding shear strength was nearly $9 \mathrm{MPa}$, which is significantly lower than the failure loads and shear strengths of all the soldered joints tested in this work. Such considerable improvement by the carbon nanomaterials suggests an alternative joining process over bonding process which exploits environmentally sensitive polymer adhesive. Another research conducted by Ufferman et al. (2018) [43] assessed single-lap adhesively bonded coated aluminium 5052 lap shear tests. The maximum force attained was $10.06 \mathrm{kN}$. However, the shear area 
was large $(\approx 40 \times 40 \mathrm{~mm})$ and the calculated shear strength was approximately $6.3 \mathrm{MPa}$, which is significantly lower than the shear strength obtained in the soldered aluminium joints examined here.

\subsubsection{Failure mode investigation}

During the lap shear tests, the failure initiated at the end of the joint and propagated until full failure occurred (i.e., detachment) as shown in Fig. 18(a). As seen, a macro-scale rough surface (rather than a sharp flat surface) has been created which is an indication of the propagation in the bulk of the material. This confers that the joint end, where shear stress is expected to be at a maximum level, was the failure initiation site. All soldered joints failed at the bulk of the solder progressively, displaying a damage-tolerant performance in which no instantaneous damage propagation was observed (referred to as adhesion failure, an undesirable damage mechanism as opposed to cohesion failure in adhesively bonded joints). Moreover, an apparent bending is observed, described here. The most dominant stress present in single-lap joints is peeling stress which is unevenly applied throughout the interface length due to out-of-plane bending moments caused by the eccentricity of the load path in such unsymmetrical joint, as seen in Fig. 18(b). This results in peeling stress-driven failure for a soldered interface, which implies that the single-lap joints provide conservative failure load prediction. A representation of this phenomenon is schematically depicted in Fig. 18(b) where the thickness of the carbon nanomaterial modified solder is exaggerated to be much higher than the thickness of adhesive at the end tabs. Such eccentricity drives a significant peeling stress which makes interfacial failure a dominant mechanism in soldered joints (adhesion failure in the case of adhesively bonded joints); however, the carbonaceous solder has exhibited a relatively higher interfacial strength than the bulk of the solder, with the failure occurring in the bulk rather than at the interface. As such, the rough surface of a typical bulk of the solder material existing on both sides of the aluminium laps have been observed. These processes can although also be studied using simulation tools involving molecular dynamics and finite element simulations [44-46], but this work focuses primarily on the development of the technology and hence the reason why only an experimental effort is presented here.

\section{Conclusions}

This article investigated the merits of using carbon nanomaterial reinforcing agent to mix with commercial tin-based solder material, C-Solder ${ }^{\circledR}$. A comprehensive microscopic examination followed by the mechanical testing procedure involving microstructure, hardness, melting temperature, creep nanoindentation behaviour, and single-lap shear joining testing with $0.01 \mathrm{wt} . \%$ and $0.05 \mathrm{wt} . \%$ carbon black, graphene, and single-walled carbon nanotube reinforced solder materials were investigated.

The melting temperature of all the carbonaceous tinbased solder achieving unprecedented joint strength was of the order of approximately $200{ }^{\circ} \mathrm{C}$, suggesting that no additional equipment is required to use these solder materials for joining processes. This also means that the thermal stresses on the aluminium substrate remained minimal compared to other joining techniques like welding and brazing.

It was observed that the hardness was improved for all cases except for G_0.01, with 5\% and 4\% improvements in CB_0.05 and SWCNT_0.05, respectively. The maximum creep indentation was improved for all samples with maximum $11 \%$ and $8 \%$, respectively, for $\mathrm{CB} \_0.05$ and SWCNT_0.05. Results for the shear performance indicated that all samples at the two contents fell within the as-received C-Solder's performance, exhibiting a progressive crack propagation. The best performance was achieved for the G_0.05 sample exhibiting minimum 52\% and $25 \%$ improvement in failure displacement and load, respectively.

The single-lap joining of A16082T6 substrates using the pristine and carbon nanomaterial reinforced solders showed comparable performance in terms of the average shear strength (i.e. failure load divided by the overlap area) and failure displacement with in-use structural adhesive bonding with a significant improvement in the exhibition of progressive failure in the bulk of the solder rather than the interface, an undesired adhesion failure in the bonded joints.

In conclusion, the newly developed solder joint material and process provides an opportunity to develop highstrength structural-grade joining of aluminium substrates with minimal surface preparation, a potential alternative to the existing adhesive-based structural joining.

Acknowledgements The authors would also like to greatly acknowledge the UKRI support in establishing the CDT in Ultra Precision Engineering (EP/L016567/1) and the EPSRC DSM NetworkPlus (EP/ S036180/1) beside the VC Fellowship from Cranfield University to sponsor the PhD research of Sara Hawi.

Funding The authors would like to acknowledge the supports from Cametics Ltd., and the UK EPSRC funded research for STRAINcomp (Ref. EP/R016828/1), the EPSRC DTP grant for 'Microstructural Study of Multifunctional Nanocomposites', Ref. EP/R513027/1) and H2020 European Regional Development Fund - IMAGE (Ref. 31R17P01422 - CU027).

Data availability The underpinning data can be accessed at Cranfield University's repository via https://doi.org/10.17862/cranfield.rd.14815 404. 


\section{Declarations}

Conflict of interest The authors declare no competing interests.

Open Access This article is licensed under a Creative Commons Attribution 4.0 International License, which permits use, sharing, adaptation, distribution and reproduction in any medium or format, as long as you give appropriate credit to the original author(s) and the source, provide a link to the Creative Commons licence, and indicate if changes were made. The images or other third party material in this article are included in the article's Creative Commons licence, unless indicated otherwise in a credit line to the material. If material is not included in the article's Creative Commons licence and your intended use is not permitted by statutory regulation or exceeds the permitted use, you will need to obtain permission directly from the copyright holder. To view a copy of this licence, visit http://creativecommons.org/licenses/by/4.0/.

\section{References}

1. J. Ballanco, Soldering vs. brazing, (2016)

2. D. Kay, Brazing Vs. Soldering, (2013). https://vacaero.com/infor mation-resources/vacuum-brazing-with-dan-kay/1345-brazing-vssoldering.html Accessed 16 Jun, 2018

3. P. Kah, R. Suoranta, J. Martikainen, C. Magnus, Techniques for joining dissimilar materials: metals and polymers. Rev. Adv. Mater. Sci. 36, 152-164 (2014). https://doi.org/10.1007/ s10856-005-6684-1

4. C.A. Walker, V.C. Hodges, Comparing metal-ceramic brazing methods, (2007) 43-50.

5. P. k. Mallick, Joining for lightweight vehicles, ed. by P. k. Mallick, Mater. Des. Manuf. Light. Veh., (Woodhead Publishing, 2010), pp. 275-308. https://doi.org/10.1533/9781845697822.2.275.

6. S. Lathabai, Joining of aluminium and its alloys, in: R. Lumley (Ed.), Fundam. Alum. Metall., (Woodhead Publishing, 2011), pp. 607-654. https://doi.org/10.1533/9780857090256.3.607

7. G. Viana, M. Costa, M.D. Banea, L.F.M. Da Silva, A review on the temperature and moisture degradation of adhesive joints. Proc. Inst. Mech Eng. Part L J. Mater. Des. Appl. 231, 488-501 (2017). https://doi.org/10.1177/1464420716671503

8. F.C. Campbell, Adhesive bonding and integrally cocured structure: a way to reduce assembly costs through parts integration, in: Manuf. Process. Adv. Compos., 2004: pp. 241-301. https://doi. org/10.1016/b978-185617415-2/50009-5

9. S.R. Urbina, D. Ayre, H.Y. Nezhad, Effect of hygrothermal cycles on mechanical performance of composite adhesively bonded joints, ECCM 2018 - 18th Eur. Conf. Compos. Mater. (2019) 24-28.

10. D. An, S. Lotfian, D. Mesbah, D. Ayre, A. Yoosefinejad, V.K. Thakur, H. Yazdani Nezhad, Ultra-thin electrospun nanofibers for development of damage-tolerant composite laminates, Mater. Today Chem. 14 (2019). https://doi.org/10.1016/j.mtchem.2019. 100202

11. Y. Liu, X. Zhang, S. Lemanski, H.Y. Nezhad, D. Ayre, Experimental and numerical study of process-induced defects and their effect on fatigue debonding in composite joints. Int. J. Fatigue. 125, 47-57 (2019). https://doi.org/10.1016/j.ijfatigue.2019.03.033

12. T. Bregar, D. An, S. Gharavian, M. Burda, I. Durazo-Cardenas, V.K. Thakur, D. Ayre, M. Słoma, M. Hardiman, C. McCarthy, H. YazdaniNezhad, Carbon nanotube embedded adhesives for realtime monitoring of adhesion failure in high performance adhesively bonded joints. Sci. Rep. 10, 1-20 (2020). https://doi.org/ 10.1038/s41598-020-74076-y
13. S. Deane, N.P. Avdelidis, C. Ibarra-Castanedo, H. Zhang, H.Y. Nezhad, A.A. Williamson, T. Mackley, X. Maldague, A. Tsourdos, P. Nooralishahi, Comparison of cooled and uncooled ir sensors by means of signal-to-noise ratio for ndt diagnostics of aerospace grade composites. Sensors (Switzerland). 20, 1-29 (2020). https://doi.org/10.3390/s20123381

14. H.Y. Nezhad, D. Stratakis, D. Ayre, S. Addepalli, Y. Zhao, Mechanical performance of composite bonded joints in the presence of localised process-induced zero-thickness defects. Procedia Manuf. 16, 91-98 (2018). https://doi.org/10.1016/j.promfg.2018. 10.175

15. R. Smith, Accomodating thermal expansion mismatch, (2014). http://www.ceramicmetalbonding.com/accomodating-thermalexpansion-mismatch/ Accessed 17 Jun 2018

16. Henkel, EAA Aluminium automotive manual - joining, Eur. Alum. Assoc. (2015) 1-31. http://european-aluminium.eu/wpcontent/uploads/2015/01/9-Adhesive-Bonding_2015.pdf.

17. H. YazdaniNezhad, Y. Zhao, P.D. Liddel, V. Marchante, R. Roy, A novel process-linked assembly failure model for adhesively bonded composite structures. CIRP Ann - Manuf. Technol. 66 , 29-32 (2017). https://doi.org/10.1016/j.cirp.2017.04.103

18. Y. Liu, S. Lemanski, X. Zhang, D. Ayre, H.Y. Nezhad, A finite element study of fatigue crack propagation in single lap bonded joint with process-induced disbond. Int. J. Adhes. Adhes. 87, 164-172 (2018). https://doi.org/10.1016/j.ijadhadh.2018.10.005

19. R.R. Chromik, R.P. Vinci, S.L. Allen, M.R. Notis, Measuring the mechanical properties of $\mathrm{Pb}$-free solder and $\mathrm{Sn}$-based intermetallics by nanoindentation. Jom. 55, 66-69 (2003). https:// doi.org/10.1007/s11837-003-0144-5

20. S.C. Tjong, Recent progress in the development and properties of novel metal matrix nanocomposites reinforced with carbon nanotubes and graphene nanosheets. Mater. Sci. Eng. R Reports. 74, 281-350 (2013). https://doi.org/10.1016/j.mser.2013.08.001

21. M. Burda, A. Lekawa-Raus, A. Gruszczyk, K.K.K. Koziol, Soldering of carbon materials using transition metal rich alloys. ACS Nano 9, 8099-8107 (2015). https://doi.org/10.1021/acsna no. 5 b02176

22. Cametics Ltd., C-SOLDER, (2017).

23. T. Khaleque, X. Zhang, V.K. Thakur, A.I. Aria, H.Y. Nezhad, Tailoring of thermo-mechanical properties of hybrid compositemetal bonded joints. Polymers (Basel). 13, 1-10 (2021). https:// doi.org/10.3390/polym13020170

24. H. YazdaniNezhad, N.P. O'Dowd, Creep relaxation in the presence of residual stress. Eng. Fract. Mech. 138, 250-264 (2015). https://doi.org/10.1016/j.engfracmech.2015.03.037

25. H. YazdaniNezhad, N.P. O'Dowd, Study of creep relaxation under combined mechanical and residual stresses. Eng. Fract. Mech. 93, 132-152 (2012). https://doi.org/10.1016/j.engfr acmech.2012.06.013

26. Y.D. Han, H.Y. Jing, S.M.L. Na, L.Y. Xu, C.M. Tan, J. Wei, Creep mitigation in $\mathrm{Sn}-\mathrm{Ag}-\mathrm{Cu}$ composite solder with Ni-coated carbon nanotubes. J. Mater. Sci. Mater. Electron. 23, 1108-1115 (2012). https://doi.org/10.1007/s10854-011-0557-9

27. Y.D. Han, H.Y. Jing, S.M.L. Nai, C.M. Tan, J. Wei, L.Y. Xu, S.R. Zhang, A modified constitutive model for creep of Sn3.5Ag-0.7Cu solder joints, J. Phys. D. Appl. Phys. 42 (2009). https://doi.org/10.1088/0022-3727/42/12/125411

28. H.Y. Jing, M. Ling, S. Nai, Indentation size effect on the hardness of a Sn-Ag-Cu solder, D (2015). https://doi.org/10.1115/ IMECE2009-10551

29. A.C. Fischer-Cripps, Nanoindentation. 21-38 (2011). https:// doi.org/10.1007/978-1-4419-9872-9.

30. Y. Nandwani, Characterization of structural adhesives using lap shear and pin and collar tests, (2015).

31. W.. Adams, R.D., Comyn, J., Wake, structural adhesive joints in engineering, 1997.

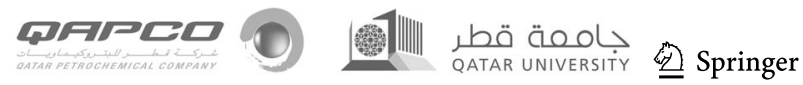


32. P. Van Son, A. Fujitsuka, K.I. Ohshima, Influence of 0.03 wt.\% carbon black addition on the performance of $\mathrm{Sn}-3.5 \mathrm{Ag}$ lead-free solder. J. Electron. Mater. 41, 1893-1897 (2012). https://doi. org/10.1007/s11664-012-2023-8

33. Z. Baig, O. Mamat, M. Mustapha, Recent progress on the dispersion and the strengthening effect of carbon nanotubes and graphene-reinforced metal nanocomposites: a review. Crit. Rev. Solid State Mater. Sci. 43, 1-46 (2018). https://doi.org/10.1080/ 10408436.2016.1243089

34. S. Iijima, T. Ichihashi, Single-shell carbon nanotubes of 1-nm diameter. Nature 363, 603-605 (1993)

35. R.M. Shalaby, Indium, chromium and nickel-modified eutectic $\mathrm{Sn}-0.7 \mathrm{wt} \% \mathrm{Cu}$ lead-free solder rapidly solidified from molten state. J. Mater. Sci. Mater. Electron. 26, 6625-6632 (2015). https://doi.org/10.1007/s10854-015-3261-3

36. B. Lim, C. Kim, B. Kim, U. Shim, S. Oh, B. Sung, J. Choi, S. Baik, The effects of interfacial bonding on mechanical properties of single-walled carbon nanotube reinforced copper matrix nanocomposites. Nanotechnology 17, 5759-5764 (2006). https:// doi.org/10.1088/0957-4484/17/23/008

37. H.Y. Nezhad, V.K. Thakur, Effect of morphological changes due to increasing carbon nanoparticles content on the quasi-static mechanical response of epoxy resin, Polymers (Basel). 10 (2018). https://doi.org/10.3390/polym10101106

38. T.R.G. Kutty, T. Jarvis, C. Ganguly, Hot hardness and indentation creep studies on Zr-1Nb-1Sn-0.1Fe. J. Nucl. Mater. 246, 189-195 (1997). https://doi.org/10.1016/S0022-3115(97)00108-6

39. V. Khanna, V. Kumar, S.A. Bansal, Mechanical properties of aluminium-graphene/carbon nanotubes (CNTs) metal matrix composites: advancement, opportunities and perspective. Mater. Res. Bull. 138, 111224 (2021). https://doi.org/10.1016/j.materresbull. 2021.111224
40. J.L. Li, Y.C. Xiong, X.D. Wang, S.J. Yan, C. Yang, W.W. He, J.Z. Chen, S.Q. Wang, X.Y. Zhang, S.L. Dai, Microstructure and tensile properties of bulk nanostructured aluminum/graphene composites prepared via cryomilling. Mater. Sci. Eng. A. 626, 400-405 (2015). https://doi.org/10.1016/j.msea.2014.12.102

41. S.M.L. Nai, Y.D. Han, H.Y. Jing, C.M. Tan, J. Wei, M. Gupta, Using nanoparticles and carbon nanotubes to enhance the properties of a lead-free solder, Nanotech Conf. Expo 2009, Vol 2, Tech. Proc. - Nanotechnol. 2009 Life Sci. Med. Diagnostics, Bio Mater. Compos. 2, 538-541 (2009)

42. K. Anam, A. Purnowidodo, D.F. Smaradhana, Effect of fillers content on mechanical strength and failure mode of aluminium bonded with epoxy-based adhesive. ARPN J. Eng. Appl. Sci. 11, 2746-2750 (2016). https://doi.org/10.1063/1.5046287

43. B. Ufferman, T. Abke, M. Barker, A. Vivek, G.S. Daehn, Mechanical properties of joints in 5052 aluminum made with adhesive bonding and mechanical fasteners. Int. J. Adhes. Adhes. 83, 96-102 (2018). https://doi.org/10.1016/j.ijadhadh.2018.02.030

44. A.K. Geim, K.S. Novoselov, The rise of graphene. Nat. Mater. 6, 183-191 (2007). https://doi.org/10.1038/nmat1849

45. Y.D. Han, S.M.L. Nai, H.Y. Jing, L.Y. Xu, C.M. Tan, J. Wei, Development of a $\mathrm{Sn}-\mathrm{Ag}-\mathrm{Cu}$ solder reinforced with Ni-coated carbon nanotubes. J. Mater. Sci. Mater. Electron. 22, 315-322 (2011). https://doi.org/10.1007/s10854-010-0135-6

46. G. Chen, F. Wu, C. Liu, V.V. Silberschmidt, Y.C. Chan, Microstructures and properties of new $\mathrm{Sn}-\mathrm{Ag}-\mathrm{Cu}$ lead-free solder reinforced with $\mathrm{Ni}$-coated graphene nanosheets. J. Alloys Compd. 656, 500-509 (2016). https://doi.org/10.1016/j.jallcom.2015.09. 178 